\title{
Designing user interface on monopoly game application for learning fraction in elementary school by using goal directed design method
}

\author{
Ariningtyas Priyahita Istiqomah $^{1}$, Danang Junaedi ${ }^{2, *}$, and Emil Robert Kaburuan ${ }^{3}$ \\ ${ }^{1}$ Telkom University, School of Computing, Informatics Department, Jl. Telkomunikasi Bandung, Indonesia \\ ${ }^{2}$ Telkom University, School of Computing, Information Technology Department, Jl. Telkomunikasi Bandung \\ ${ }^{3}$ Bina Nusantara University, Information System Management, Jl. Kebon Jeruk Jakarta - Indonesia
}

\begin{abstract}
Learning achievement is a measure of success after following the learning process. While the mathematics learning achievement of 5th grade elementary school students is low, as evidenced by the daily recapitulation data value of students who still score below the Minimum Exhaustiveness Criteria. According to the teacher the cause is the number of students who have not mastered the fraction material as the basis of mathematics material taught in class 5. So that required handling to achieve optimal results. According to research by Elvi Mailani, the Monopoly game used as a fractional math learning tool for elementary school children can have a positive impact by training children to hone their skills. But in this study, the media used less effective because it requires special handling to achieve goals and more optimal results. Based on these problems, a model of user interface for prototype application of fractional math monopoly game for elementary school students was designed. The goal directed design method is used as a design method that focuses on user goals. Based on the result of usability evaluation for the user interface model using QUIM obtained a percentage of $91.56 \%$. So that the user interface model has fulfilled the usability element as a learning fraction media in Elementary school.
\end{abstract}

\section{Introduction}

The benchmark of success for students after attending the learning process at school at a certain period is learning achievement, which is influenced by the level of learning interest of children as internal factors and learning environment around the child as an external factor. Based on the recapitulation of 5th grade daily grade scores in one of the primary schools in Bandung obtained from the teacher, most of the children's mathematics score is less than the KKM score (Minimum Exhaustiveness Criteria). One of the contributing factors (from the interview with the teacher) is the number of students who have not mastered the fractional material that is the basis of the mathematics material taught in 5th grade of elementary school.

Based on the research of Elvi Mailani [1], the monopoly game as a fractional math learning medium has a positive impact because it motivates the children to learn and practice to understand the fractional math materials. However, the media display used is not effective because it still requires teachers so that children can understand the display content of the media when operating it. This resulted in the absence of significant appeal for children to use it, so the purpose of the task provided less well conveyed to the child because they cannot operate it independently.
In order to achieve the goal of increasing the understanding of fractional math for elementary school children, the monopoly game from Elvi Mailani's research continues with building a mobile-based monopoly game application in order to facilitate the child to achieve the learning objectives in an effective way. Game Based Learning is a game concept used as a reference and is applied into the real world to engage users [2]. In building a monopoly game application that can support the learning of fractional math, a good user interface is needed so that children can easily understand and can carry out the tasks that exist in the application. This is because if the user interface is not well designed though the concept of a well-developed game can cause the user to feel confused, frustrated and inefficient in its use [3]. Mobile devices can be used as a media for learning, this is an approach to electronic learning also known as mobile learning [4].

In this study, especially on the design, using the method of Goal Directed Design (GDD), which is a method of designing user interface that focuses on the goal [5]. After designing, proceed with testing to determine the level of usability by evaluating aspects of Quality in Use Integrated Measurement (QUIM). QUIM has the most complete and very appropriate aspects to be used as a benchmark of usability level towards achieving the goals (goals) of the applications to be built [6].

\footnotetext{
* Corresponding author: danangjunaedi@,telkomuniversity.ac.id
} 


\section{User interface modelling flow}

The Goal Directed Design (GDD) method is used as research methodology in designing user interface model, consisting of research, modelling, requirement definition, framework definition, refinement, support [7] and subsequently user interface model will be tested using Quality in Use Integrated Measurement (QUIM) [8] where the results will be analyzed and drawn conclusions. Based on the cycle in the GDD method, in Fig. 1 a flowchart is made which contains the activities of each stage during the study.

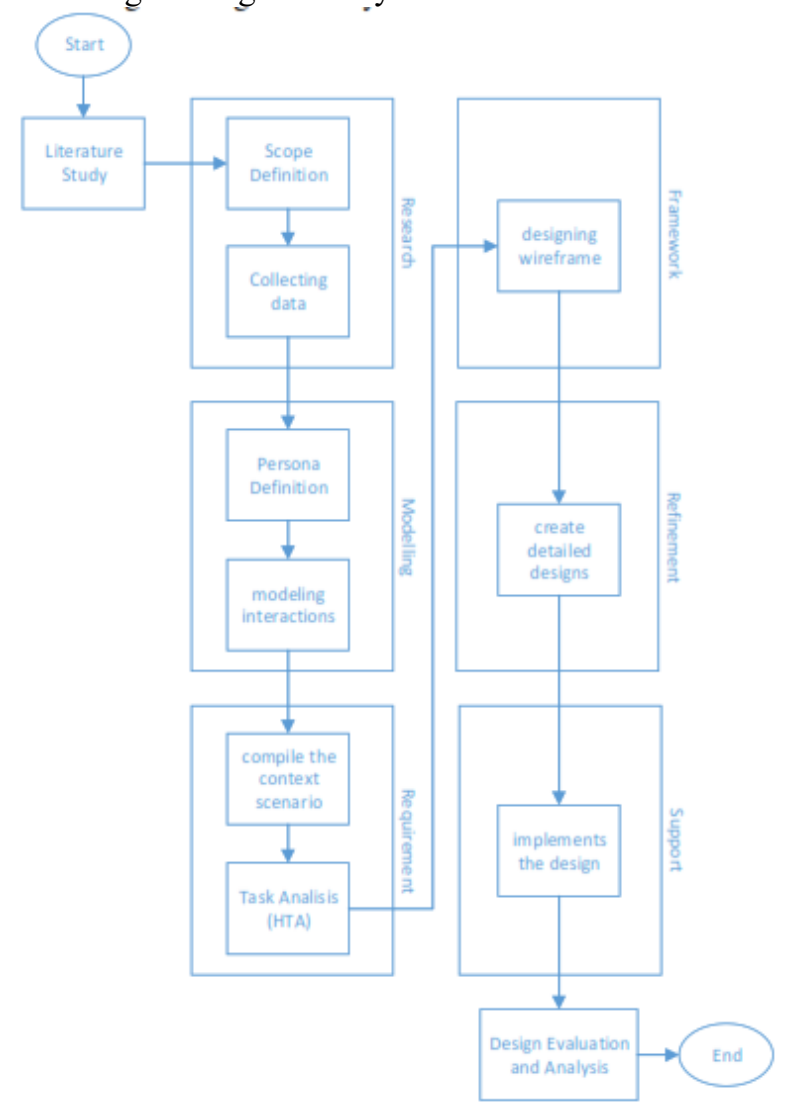

Fig. 1. User interface modelling flow.

\subsection{Research}

At this stage, observations and interviews with grade 5 primary school students are conducted to obtain qualitative data about the user's insight in detail and the purpose and motivation of users in learning the fractional math. In this study involved 5 children as randomly selected respondents. The retrieval of respondents is based on research conducted by Jakob Nielson Norman [9], which states that in conducting research with the respondents as many as 5 people is enough because the test results with the number of respondents meet the required requirements of reaching $85 \%$.

The conclusions of the research stages obtained the objective understanding of the mathematical fractions so that children can improve mathematics learning achievement by motivating children to continue to practice with the presentation of more interesting material. Therefore, further information is extracted persona child with a goal that has been obtained, the goal will be the basis of the prototype development of the game of monopoly for math fractions

\subsection{Modelling}

At this stage the data processing has been obtained into the form of user persona in which there is a combination of different patterns of behaviors, attitudes, talents, abilities, motivations and goals of every 5-year-old primary school children aged 10-11 years. The resulting pattern of behavior is derived from the results of observations and interviews conducted to users and teachers to be the basis in determining the type of persona and mental model for the persona [10] that will be used in modelling the user interface.

\subsection{Requirement definition}

Deeply defined needs are developed into the context of scenarios and conceptual models implemented at this stage. To identify and analyze the required tasks, additional hierarchical task analysis (HTA) methods are required [11]. In addition, before designing the context of the scenario and conceptual model, it is necessary to define the user persona goals in detail and their needs can be seen in table 1 .

Table 1. Requirement definition.

\begin{tabular}{|l|l|}
\hline \multicolumn{1}{|c|}{ Goals } & \multicolumn{1}{c|}{ Requirement } \\
\hline $\begin{array}{l}\text { Getting easy to } \\
\text { solve fractional } \\
\text { problems that are } \\
\text { considered the } \\
\text { most difficult. }\end{array}$ & $\begin{array}{l}\text { - Features in the form of help } \\
\text { to choose the right answer } \\
\text { by removing two options } \\
\text { from four options } \\
\text { - Features in the } \\
\text { multiplication table form as } \\
\text { a reminder to help the } \\
\text { calculation process } \\
\text { - Features in the form of a } \\
\text { reminder of the problem- } \\
\text { solving steps to help answer } \\
\text { the question }\end{array}$ \\
\hline $\begin{array}{l}\text { Exercise skills to } \\
\text { solve various } \\
\text { types of fractional } \\
\text { problems with } \\
\text { good work flow } \\
\text { different levels of questions }\end{array}$ & $\begin{array}{l}\text { - Features evaluation answers } \\
\text { when making mistakes in } \\
\text { answering questions }\end{array}$ \\
\hline $\begin{array}{l}\text { Gain an award } \\
\text { after achieving } \\
\text { success }\end{array}$ & \begin{tabular}{l} 
Reward feature \\
\hline
\end{tabular}
\end{tabular}

\subsection{Framework definition}

At this stage the user interface design is done which contains the structure of the display and layout of the game application of mathematical fractions in wireframe. The resulting wireframe describes the placement of content [12]. The design of this user interface is made based on the scenarios and requirements that have been prepared in the requirement definition stage to create the initial design of user 
appearance and behavior when interacting with the game application of fractional math monopoly. Fig.2 is an example of a wireframe that has been created.

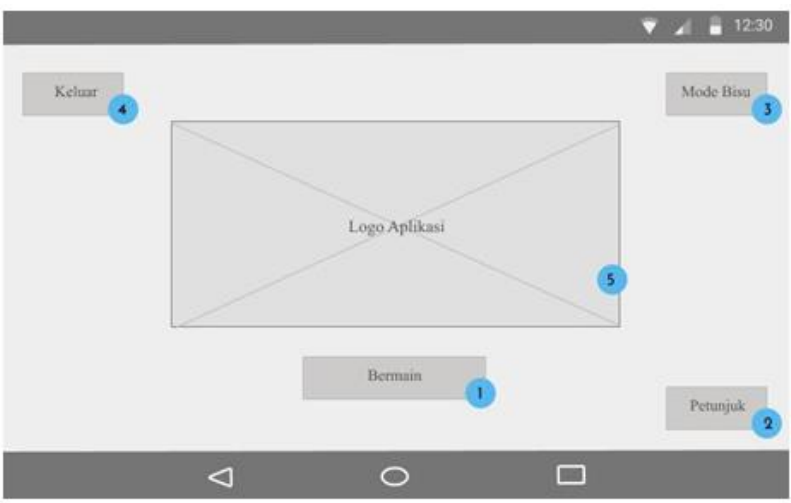

Fig. 2. Sample wireframe for main page.

\subsection{Refinement}

At this stage generated a mock up design in accordance with the layout that has been created at the framework definition stage. In the making of the mock up the selection of colors, fonts, icons used in the application display game monopoly mathematical fractions tailored to elementary school children (10-11 years). In this study, the mockup is built with a standard size Android smartphone that is $1280 \times 800$ pixels. Mockup is created using the proto.io app to create an interface display based on the previously generated wireframe. Below is an example of a mockup of the main page of fractional math game applications (MONPEC). Examples of mockups that have been made can be seen in Fig.3 to Fig 6 below:

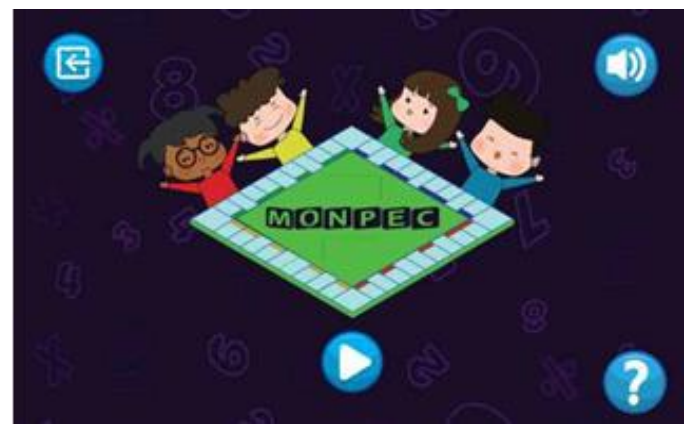

Fig. 3. Sample mockup for main page.

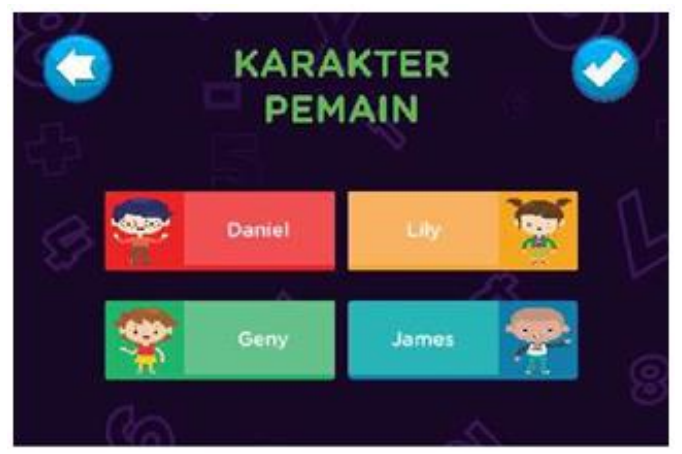

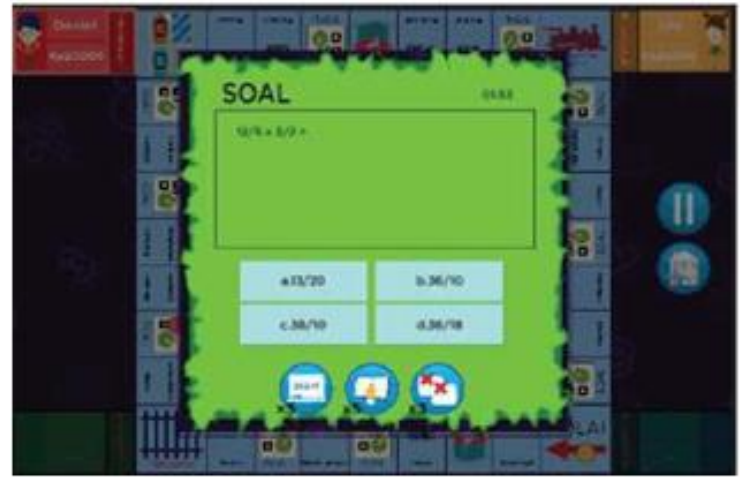

Fig. 5. Sample mockup for question for math fractions.

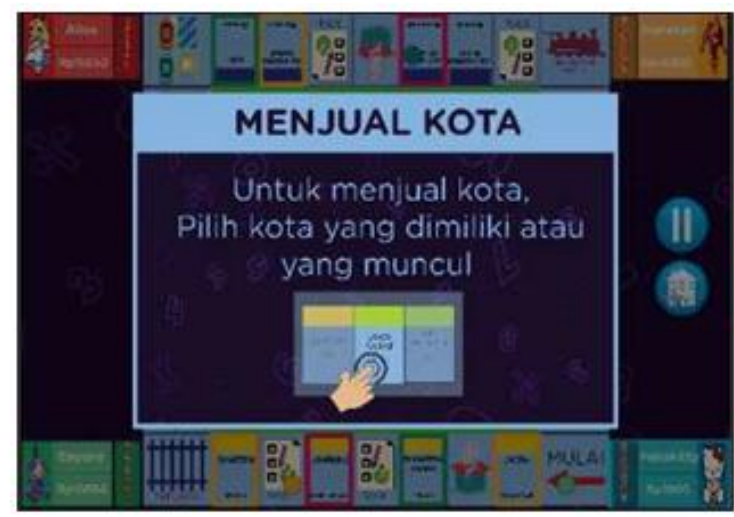

Fig. 6. Sample mockup for city sales.

\subsection{Support}

Here, the user interface design that has been generated in the previous stage (refinement) is implemented into the prototype of an Android-based app for a fractional math monopoly game.

\section{Testing and Analysis of test results}

Testing is done in order to know what should be improved so that the prototype built can achieve the objectives that have been set in accordance with the characteristics of the user. Before performing the test, a test plan or scenario is required for testing to be performed properly. The test scenario can be drawn, consisting of (1) Determining the list of respondents that are 5th grade primary school students aged 10 to 11 years (2) Lend a smartphone that has MONPEC application prototype installed. (3) Observe user behavior when running prototype as a real form of judgment to reduce nonconformity given by respondent during interview. (4) As long as the user runs the MONPEC application, the user is given an unstructured and direct interviewed question to get answers to the questionnaire that has been made according to the QUIM factors. (5) Perform processing of test data to get usability percentage value. We do three times usability testing, recapitulation of test results can be seen in Fig. 7 below:

Fig. 4. Sample mockup for character selection. 


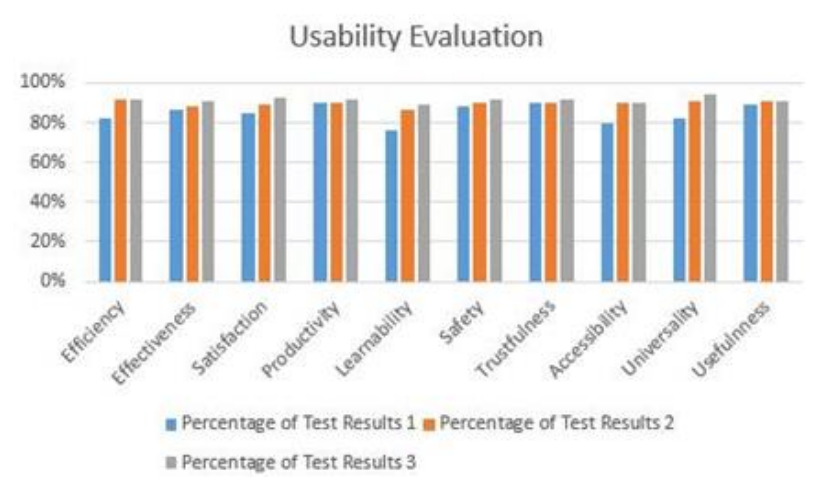

Fig. 7. Usability evaluation result.

The average usability value in the first test was $84.89 \%$. Factors that still need to be improved are efficiency, learnability, accessibility, and universality. This is because there are users who do not recognize icons in the help feature (multiplication table feature, reply tips feature, and redundancy feature of two answer option options) and do not know the layout. So, the user takes a long time to find the help feature in solving problems that are considered difficult for them. Based on these findings it is necessary to improve the design on the second iteration.

From the result of percentage of second iteration test that got average equal to $89,73 \%$ which belongs to category excellent, so that prototype can be used, but based on observation at the time will be used apparently there are some findings as follows:

- Lack of conformity of User Interface display with design principle caused by inconsistent use of button and its placement.

- The use of characters that must obtain permission if you want to use the character from the party who made the character.

- There is a mistake on some of the questions given because the problem has a level of difficulty that exceeds the ability of 5th grade primary school children in general

To fix the shortcomings of the design on the second iteration made some adjustments in the third iteration. To correct the design flaws in the second iteration some adjustments were made in the third iteration. After testing for design on the third iteration obtained an average usability of $91.56 \%$. This indicates that improving the user interface design performed on the last iteration provides a more user-friendly and optimized result by moving from one task to another and understanding and facilitating the user in answering the given problem correctly.

\section{Conclusions}

Based on the results of analysis and implementation of user interface model in game MONPEC by using method of Goal Directed Design in its design can be concluded, that:

- The user interface model is designed to be a monopoly game display in general, but there are some additions and feature changes to support game applications that provide learning by using more interesting methods. Some of the changes and additions to these features include, as follows:

a) The existence of additional features in the form of questions contained in a particular plot of four plots of matter from each side of the board game.

b) Created three levels of problems for children to facilitate in solving problems in a shorter time and in accordance with the understanding of material owned by the child. This feature appears when the user enters the question plot and each level of the problem has different work time constraints.

c) A reward feature that aims to motivate the child to do the task correctly and encourage the child to work on the most difficult questions. This reward feature is tailored to each level of the question, where the more difficult the level of the selected matter then give the reward the greater. But if the answer is wrong then the greater the reduction of the score given to the player.

d) Help features (multiplication tables, subtraction of two options for answer options, and answer tips) to make it easier to solve problems that are deemed most difficult by the child with each feature of assistance has a limit on the number of uses.

e) Features evaluate answers that explain in detail the problem-solving steps to get the most appropriate answer, so as to make the child know the exact answer of the problem that has been done before. This feature only appears if the child is wrong in choosing the answer.

f) Provided the option to get out of jail by doing random questions without help. But if the player is wrong in answering the matter then the player remains in prison.

g) The general fund plot with the opportunity plot is merged into one plot (mystery box plot), this is due to the limitations of screen size

- Testing of the user interface model on MONPEC game application prototype using Quality in Use Integrated Measurement method obtained a percentage of $91.567 \%$ which means that the design has met the needs of the user as a learning gamebased application and usability elements. But in this study still has not done testing on the impact of the use of applications for the ability of users in improving user learning achievement after using MONPEC application.

\section{References}

1. E. Mailani, Upaya Meningkatkan Hasil Belajar Matematika pada Materi Pecahan melalui Permainan Monopoli Pecahan 4 (2015)

2. A. Pho, A. Dinscore, Instruction Section - Game Based Learning, Tips and Trends Intructional Technologies Commitee (2015) 
3. M. K. Sabariah, V. Effendy, D. Junaedi, Interaksi Manusia dan Komputer (Bandung: Diandra Creative Mirza, 2015)

4. A. Kukulska-Hulme, J. Traxler, Mobile teaching and learning, in Mobile Learning: A Handbook for Educators and Trainers, A. Kukulska-Hume and J. Traxler, Eds. (London: Routledge, 2005)

5. W. O. Galitz, The Essential Guide to User Interface Design (Wiley Publishing, 2007)

6. S. N. Laila, M. K. Sabariah and D. D. J. Sumawi, UI design of collaborative learning app for final assignment subject using goal-directed design, Information and Communication Technology (ICoICT) (2016)

7. H. Debberly, Alan Cooper and the Goal Directed Design Process 1 (2001)

8. A. Seffah, M. Donyaee, R. B. Kline, H. K. Padda, Usability measurement and metrics: A consolidated model, Software Qual J. 14, 2, 166-172 (2006)

9. J. N. Norman, Nielsen Norman Group [Online] Available: https:/www.nngroup.com/articles/whyyou-only-need-to-test-with-5-users/. (Accessed 17 June 2017)

10. I. Yound, Mental Model in Aligning Design Strategy with Human Behavior (New York, Rosenfeld Media, 2008)

11. D. Diaper, N. A. Stanton, Hierarchical Task Analysis, in The Handbook of Task Analysis for Human-Computer Interaction (London, Lawrence Erlbaum Associates, Inc (EA), 2004)

12. usability.gov, Wireframing [Online]. Available: https://www.usability.gov/how-to-andtools/methods/wireframing.html.(Accessed 2017 September 20) 